\section{BIOTECNOLOGÍA INDUSTRIAL}

\author{
Manuel Rendueles \\ Universidad de Oviedo \\ mrenduel@uniovi.es \\ Mario Díaz \\ Universidad de Oviedo \\ mariodiaz@uniovi.es
}

Cómo citar este artículo/Citation: Rendueles, M. y Díaz, M. (2014). "Biotecnología industrial". Arbor, 190 (768): a155. doi: http://dx.doi.org/10.3989/arbor.2014.768n4009

Recibido: 9 junio 2014. Aceptado: 14 julio 2014.

RESUMEN: La Biotecnología Industrial, como campo tecnológico de aprovechamiento industrial de materiales biológicos, se conforma como un área muy amplia con aplicaciones nuevas y tradicionales, que ha incorporado los nuevos desarrollos iniciados con el conocimiento del material genético, así como las nuevas tecnologías precisas para la obtención eficiente de los productos. En este trabajo se lleva a cabo una descripción de distintos productos de base biológica con interés comercial, así como unos breves comentarios sobre los procesos para su obtención.

PALABRAS CLAVE: Biotecnología industrial; productos comerciales; biocatalizadores; procesos; biorreacciones; separaciones.

\section{INDUSTRIAL BIOTECHNOLOGY}

Copyright: (c) 2014 CSIC. Este es un artículo de acceso abierto distribuido bajo los términos de la licencia Creative Commons Attribution-Non Commercial (by-nc) Spain 3.0.

ABSTRACT: Industrial biotechnology, is a broad area involving the industrial benefit of biological materials, that is applying efficiently the new developments following the genetic material knowledge, and the new technologies necessary for product development. A short description of the different products of commercial interest are here presented, followed by brief comments on the processes used to be obtained.

KEYWORDS: Industrial Biotechnology; commercial products; biocatalysts; processes; biorreactions; separations. 


\section{INTRODUCCIÓN. ¿QUÉ ES LA BIOTECNOLOGÍA INDUSTRIAL?}

La historia de la Biotecnología puede ser descrita en diferentes términos. En ocasiones se menciona en relación con los desarrollos del conocimiento del material genético, otras veces en el aprovechamiento científico de microorganismos y enzimas, otras veces yendo a la antigüedad buscando la utilización tecnológica tradicional de los mismos. Los desarrollos científicos y tecnológicos crecientes sobre la estructura y transformaciones de los materiales biológicos han puesto de actualidad esta área, no solo por los nuevos productos o transformaciones, sino también por la aplicación de estos conocimientos a procesos tradicionales, de miles de años o de décadas. Cuando se quiere ordenar los avances relacionados con este campo, es frecuente mencionar las aplicaciones en los campos agrario, de la salud, del medio ambiente, marino.... y en procesos industriales, la denominada biotecnología industrial (BI) o blanca. La definición de esta última puede también hacerse en términos más amplios o reducidos, como disciplina más moderna, o más tradicional y con mayor peso económico.

Consideraremos la Biotecnología Industrial como el campo relacionado con las Tecnologías para producir bienes y servicios usando organismos y materiales biológicos encontrados en la naturaleza, modificados o no.

Este enfoque, amplio, permite crear una estructura globalizadora y de límites más claros, en la que aparecen procesos con diferente contribución de los conocimientos más recientes. Puede considerarse así la aplicación para desarrollar nuevos productos, modificar procesos tradicionales haciéndolos más competitivos, y para reducir el impacto ambiental. La Biotecnología Industrial se asocia generalmente con el desplazamiento de materias primas fósiles por otras basadas en materiales biológicos o renovables, así como también con el ahorro energético, de residuos, e inferior impacto ambiental.

Bajo el punto de vista social y tecnológico suelen indicarse algunas posibles ventajas o aspectos impulsores de la BI, así:

- Diversos aspectos de competitividad, como el ahorro de agua y de energía; y los beneficios económicos relacionados con ellos.

- La seguridad y diversificación de suministro materias primas, de combustible, alimentos, agua.

- La demanda del consumidor de productos diferen- ciados, y en particular la competencia internacional creciente que busca esta diferenciación.

- La visión de que la BI tiene menos costes de inversión, de operación y mayor eficacia tecnológica, al trabajar con frecuencia en condiciones más suaves.

- Las exigencias de procesos sostenibles, para las que parece que los procesos de biotecnología industrial pueden tener ventajas.

- Las políticas gubernamentales, impuestos, apoyo a I+D, prestamos, apoyo a agricultura o apoyo comercial a productos, basados en la preparación de una sociedad de futuro. En todo caso el éxito de la biotecnología industrial debe producirse a través de ventajas económicas.

Las herramientas que se han desarrollado o mejorado son numerosas, tanto en el uso de enzimas y microorganismos: Técnicas ómicas, in silico, Ingeniería de proteínas, Ingeniería metabólica, como en las de post-tratamiento del bioprocesado, mezcla, fluidización, fenómenos superficiales, cromatografía y membranas, separación in situ y procesos acoplados, así como instrumentación y control.

El desarrollo tecnológico y económico del sector ha sido enorme en los últimos 30 años, tanto en la mejora de procesos tradicionales como en la creación de nuevos productos, y de nuevos procesos, aunque algunos pensaban que llegaría incluso antes. Sigue habiendo no obstante una cierta conciencia limitada de cómo acceder a la BI, como desarrollar las tecnologías, así como en algunos casos como tener la aceptación social.

Consideraremos ahora los diversos procesos industriales de base biológica, haciendo una división en tres campos:

- Los procesos donde se utilizan microorganismos.

- Procesos de utilización de enzimas.

- Procesos de aprovechamiento de materiales biológicos.

Un esquema general de los diferentes procesos y productos que se pueden obtener se resume en la Tabla 1.

\section{PROCESOS DE PRODUCCIÓN CON CÉLULAS}

La mayoría de los procesos biotecnológicos están basados en microorganismos. Los organismos más frecuentes son las bacterias y levaduras, pero también 
Tabla I. Esquema general de los Bioprocesos Industriales

\begin{tabular}{|c|c|c|c|}
\hline Biocatalizador & Fases & Productos & Ejemplos \\
\hline \multirow{9}{*}{ Células } & \multirow{6}{*}{ Liquida } & Productos quimicos & Bioetanol, ácidos orgánicos, bioplasticos \\
\hline & & Enzimas & Amilasas, celulasas \\
\hline & & Inóculos & "Starters", levadura del pan \\
\hline & & Productos farmaceúticos & Antibióticos, hormonas, esteroides,... \\
\hline & & Productos alimentarios & Bebidas fermentadas, vitaminas, \\
\hline & & Tratamientos ambientales & Tratamiento de aguas, de COV, metano \\
\hline & \multirow{3}{*}{ Solida } & Alimentos & Queso, productos cárnicos \\
\hline & & Tejidos & Piel, tejido hematopoyético \\
\hline & & Residuos y energia & Biogas, compost \\
\hline \multirow{4}{*}{ Enzimas } & Acuosa & Productos quimicos & Aminoácidos, glutamato \\
\hline & Orgánica & Sintesis orgánica & Uso de Hidrolasas (Lipasas, proteasas) \\
\hline & \multirow{2}{*}{ Sólida } & Hidrolisis & Hidrólisis de almidones \\
\hline & & Productos comerciales & Detergentes enzimáticos \\
\hline \multirow{6}{*}{ Sin biocatalizador } & \multirow{4}{*}{ Sólida } & Vegetal- Materiales de construcción celular & Papel \\
\hline & & $\begin{array}{l}\text { Vegetal- Materiales de almacenamiento de } \\
\text { hidratos de carbono }\end{array}$ & Azúcar \\
\hline & & Animal Grasas & Manteca, Sebos \\
\hline & & Animal órganos & Hormonas \\
\hline & \multirow{2}{*}{ Liquida } & Vegetal & Aceites \\
\hline & & Animal- Proteinas & Lactosuero, sangre de mataderos, colas. \\
\hline
\end{tabular}

se pueden utilizar otros cultivos celulares, incluyendo tejidos u órganos. Por sus diferentes implicaciones desde el punto de vista del bioproceso distinguiremos los procesos en fase líquida y en fase sólida.

\subsection{Fase líquida}

\subsubsection{Bebidas alcohólicas}

Son todos procesos conocidos desde hace muchos siglos, pero en la que constantemente se buscan innovaciones y modificaciones que den lugar a nuevos productos o productos con diferentes características. En esencia estas bebidas son el resultado de la fermentación alcohólica de diversos sustratos, bien cereales o bien frutas. Así, cerveza es el nombre genérico que se da a toda bebida fermentada fabricada a base de malta (cebada germinada), lúpulo, agua y levaduras del género Saccharomyces. El vino es el zumo de las uvas también fermentado por levaduras del género Saccharomyces. Por último, La sidra se puede definir como el líquido resultante de la fermentación del mosto de manzana por levaduras del mismo género: Saccharomyces.
El valor nutritivo de las bebidas alcohólicas ha estado adscrito en el contexto cultural europeo al vino, la cerveza y la sidra, que habían formado durante siglos parte de la dieta de la población. El consumo de bebidas alcohólicas es una constante a lo largo de la historia de la civilización.

Cerveza y vino han sido las de mayor consumo a lo largo de la historia y darán lugar a lo que, desde un punto alimentario, se ha considerado como "las dos Europas": el sur vitivinícola y el norte cervecero.

En el vino y la sidra, es normal que además de la fermentación alcohólica tenga asimismo lugar la denominada fermentación maloláctica, mediante la cual las bacterias lácticas y en concreto las de la especie Oenococcus oeni transforman el ácido málico existente en el medio a ácido láctico, proceso muy conveniente desde el punto de vista organoléptico ya que rebaja la excesiva acidez que tendría el producto.

\subsection{2. Ácidos Orgánicos}

Vinagre. Proviene de bebidas (vino, cerveza, sidra) que utilizan bacterias acéticas (Acetobacter, o Gluconobacter). Hay métodos lentos y rápidos, precisándo- 
se del aporte de grandes cantidades de oxigeno que se introducen mediante aireación.

Ácido láctico. Se obtiene de la lactosa por fermentación mediante diferentes tipos de Lactobacillus.

Ácido cítrico. Se obtiene con Aspergillus niger o Candida guilliermondii a partir de melazas en bandejas o en profundidad con tiempo de fermentación de menos de 7 días. Se puede obtener por extracción de las frutas (cítricos), pero es más sencillo y barato el proceso fermentativo. Se usa como conservante y antioxidante natural para conservas, vegetales, caramelos, gominolas.

Otros ácidos por ejemplo glucónico a partir de glucosa fermentada con $A$. niger. Un ejemplo con el que se tiene experiencia es la producción de ácido Lactobiónico a partir de suero lácteo con Pseudomonas taetrolens como inóculo (Figura 1). Este es un campo de gran desarrollo industrial buscando cada vez ácidos más específicos con aplicaciones alimentarias y farmacológicas.

\subsubsection{Grasas y aceites}

Normalmente se producen a partir de la extracción directa de productos naturales, no es habitual que se obtengan por fermentación. Se necesita regular bien las relaciones $\mathrm{C} / \mathrm{N}$ y $\mathrm{C} / \mathrm{P}$ que deben ser elevadas, un $\mathrm{pH}$ ácido y condiciones aerobias, utilizándose en particular de melazas o suero lácteo como sustratos. El ácido $\mathrm{Y}$-linolénico se obtiene fermentando los sustratos con hongos del género Mucor.

\subsubsection{Polisacáridos}

Se producen en procesos mesófilos y aeróbicos. El aumento de viscosidad dificulta el proceso productivo. La goma xantana (E-415) se obtiene de Xanthomonas campestris en medios con glucosa. El dextrano lo produce entre otros el Leuconostoc mesenteroides mediante un enzima extracelular que posee. Se usa en jarabes, helados y confituras.

Figura 1. Esquema del bioproceso fermentativo de producción de ácido lactobiónico a partir de lactosuero

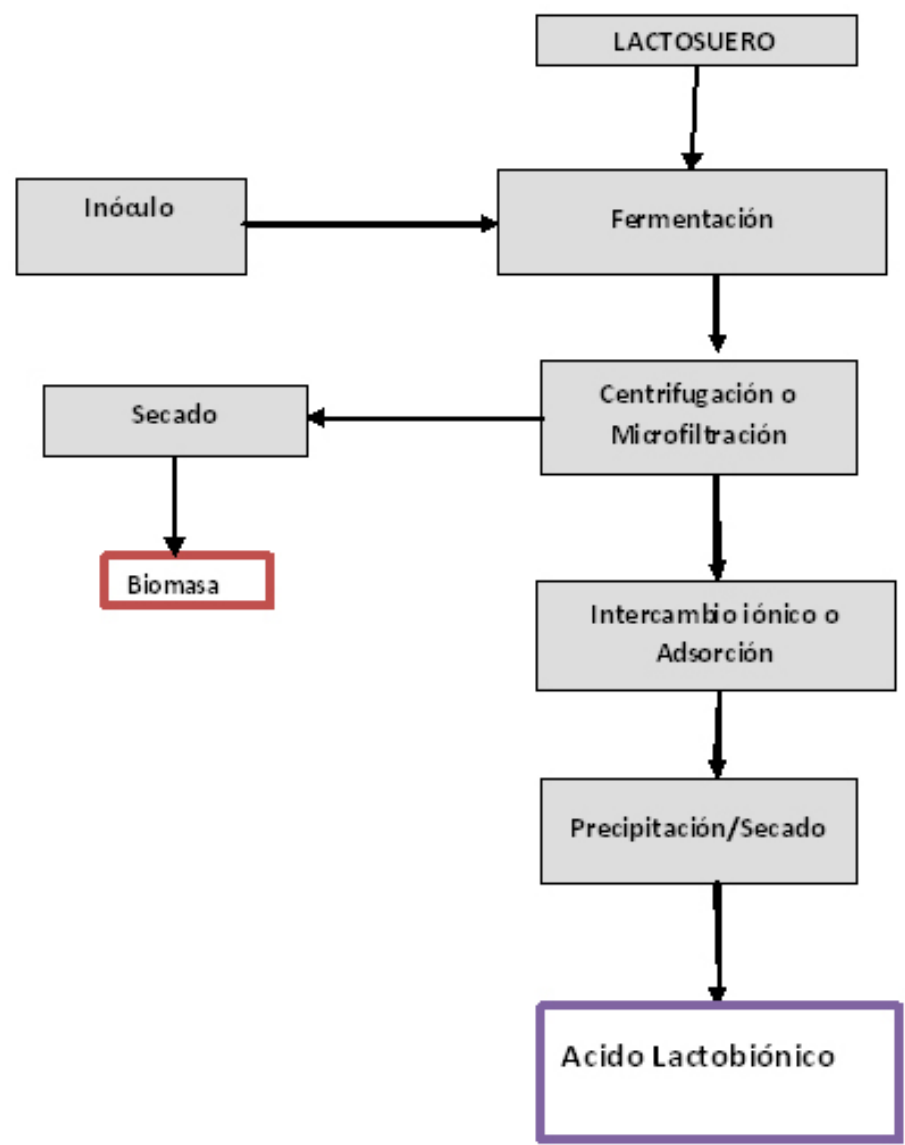




\subsubsection{Proteína unicelular}

La mayoría de la proteínas celulares utilizadas en alimentación humana y animal tienen procedencia secundaria (los microorganismos son subproductos de otras fermentaciones. La digestibilidad, aproximadamente del $95 \%$ en levaduras y $50-75 \%$ en algas, es un parámetro de gran interés. Se han utilizado un gran número de sustratos, por ejemplo melazas, hidrolizados de madera, etanol, residuos orgánicos, etc. Las levaduras son los microorganismos más comunes en este tipo de producción, con $\mathrm{pH}$ de trabajo de 4 a 6. Se usa sobre todo Saccharomyces cerevisiae en reactores continuos que permiten aireación y agitación óptimos evitando producir alcohol. La levadura producida se trata con sosa para quitar el amargor y se lava con ácido fosfórico. Se utilizan también muchas bacterias (Methylophilus, Methylomonas) y actinomicetos usando como sustratos residuos agrícolas y forestales. Y también mohos y hongos superiores en diversos procesos, para setas en purines o compost sintético. Finalmente algas que pueden crecer de forma autótrofa (con luz de $700 \mathrm{~nm}$ y $\mathrm{CO}_{2}$ ) o heterótrofa (con carbono orgánico y energía).

\subsubsection{Inóculos}

Los inóculos o starters se producen para ser usados como biocatalizadores en bioprocesos. Se usan mucho en industria alimentaria, para conservar alimentos y mejorar las propiedades funcionales y organolépticas. Los más conocidos están en industria cárnica, láctea y de panadería. Por ejemplo las levaduras de pan, $S$. cerevisiae, se producen utilizando melaza como substrato suplementado con N, P y biotina (vitamina B7) en reactores continuos y aerobios consiguiéndose rendimientos de biomasa de $0,54 \mathrm{~kg} / \mathrm{kg}$ (Yx/s). En la industria láctea, para quesos, se usan Streptoccocus cremoris, o Penicillium entre otros; o para la fabricación de yogures Lactobacillus bulgaricus. En la industria cárnica para la producción de embutidos curados se usan Lactobacillus plantarum, Pedioccocus cerevisiae o Micrococcus (reductoras de nitrato a nitritoque es un conservante). También se usan levaduras para fermentaciones alcohólicas, para producción de cerveza- S. cerevisiae (cerveza ale- crecimiento en superficie) o Saccharomyces carlsbergensis (cerveza lager- crecimiento en profundidad).

\subsubsection{Enzimas}

Son proteínas que actúan como catalizadores de las reacciones químicas de los sistemas biológicos. Exis- ten unas 400 enzimas de interés industrial, habiéndose utilizado en alimentación desde hace muchos años, por ejemplo la quimosina (cuajo) del estómago de los rumiantes para hacer queso. Algunos ejemplos son los siguientes:

a) Extracelulares, producidas en la parte exterior de las membranas celulares entre ellas están:

- Proteasas que hidrolizan proteínas, como las proteasas de Bacillus subtilis utilizadas para ablandar carnes o hidrolizar material gelatinoso.

- Amilasas Degradadoras de almidón para producir azúcares fermentables en bebidas alcohólicas o harina, así $\alpha$-amilasas o amiloglucosidasas (obtenidas de A. niger).

- Hemicelulasas como pectinasas (también obtenidas de A. niger) que se utilizan para la extracción de zumos de frutas.

- Celulasas que rompen células y tienen un uso alimentario se pueden obtener de Trichoderma reesei.

- Lipasas (obtenidas principalmente de hongos y levaduras) se usan en detergentes, alimentación, biodiesel.

- Otras, por ejemplo lactasas o dextranasas tienen amplios usos en alimentación.

b) Intracelulares- son mucho menos usadas, ya que para obtenerlas es necesario romper, y por tanto inactivar el microorganismo productor. Entre ellas están:

- Glucosaisomerasa para producir fructosa en jarabes.

- Lactasas de diversas especies de Saccharomyces y Bacillus.

\section{La producción de enzimas}

Las extracelulares son más baratas por ser más fácil su recuperación y purificación. Normalmente se producen en fase sumergida (líquida) mediante procesos aerobios, y el factor limitante suele ser el aporte de oxígeno. Como medio de cultivo se puede usar salvado de cereales o de arroz, o fuentes de carbono como melazas. El tiempo de fermentación varía según el proceso desde unas pocas horas hasta unos 12 días. Los microorganismos más utilizados son de las especies Bacillus y Aspergillus. La concentración típica de enzima suele ser 5-10\% de la masa celular. 


\subsubsection{Productos industriales}

Son productos químicos de gran uso en muchos campos industriales, por ejemplo:

a) Bioetanol (se usa particularmente en Brasil y USA). Las materias primas habituales son azúcares de caña, remolacha, almidones de maíz. El $95 \%$ se obtiene con $S$. cerevisiae, pero también se usa Clostridium thermocellum o Zhymomonas mobilis que normalmente trabajan en anaerobiosis. En los últimos años se han implantado varias factorías de bioetanol en España.

b) Acetona y butanol. Puede obtenerse de almidones utilizando Clostridium acetobutylicum. La acetona tiene mucha utilidad en productos con grasas y aceites y el butanol en detergentes.

c) Butanodiol $(2,3)$. Es más barato por vía química pero se puede obtener a partir de hexosas y pentosas, mediante Klebsiella oxytoca, aunque no es económicamente competitivo en la actualidad.

d) Obtención de bioplásticos. Los bioplásticos se obtienen a partir de diversos materiales renovables, concibiéndose como materiales biodegradables. El almidón con algunos plastificantes (como glicerina) se utiliza como termoplástico. Muchos se obtienen por fermentación: por ejemplo el PululanoPolisacárido de glucosas unido por enlaces C1-C6 a los que no atacan las amilasas, puede usarse para cápsulas. Se obtiene de Pullularia o Aerobasidium pullulans. El polihidroxibutirato es un material de almacenamiento energético, que se puede obtener de diferentes fuentes, por ejemplo de Alcaligenes eurotrophus. Es parecido al polipropileno y puede usarse como soporte para liberación controlada de medicamentos o alimentos. El polilactato, plástico transparente parecido al polietileno, se puede obtener por polimerización de ácido láctico obtenido por ejemplo por fermentación de glucosa de almidón de maíz.

\subsubsection{Productos de uso alimentario}

a) Aminoácidos. Algunos como glicina, L-cisteina (L-cistina) se obtienen por fermentación mientras que otros (L-asparragina, L-leucina, L-tirosina) se obtienen por purificación de hidrolizados proteícos. Se usan como nutrientes y saborizantes en alimentos y fármacos.

b) Aditivos de sabor. Nucleósidos. La L-lisina, aminoácido esencial, se puede obtener mediante Corynebacterium glutamicum a partir de oxala- cetato del ciclo del ácido cítrico, vía L-aspartato con aspartato kinasa. Metionina y L-treonina se producen también por fermentación aunque su producción podría competir en un futuro con la de plantas transgénicas en las biofactorias.

c) Vitaminas:

I. Vitamina C. La D-glucosa (a 150 bar y catalizador de $\mathrm{Ni}$ ) se reduce a $\mathrm{D}$-sorbitol. Este se convierte en L-sorbosa mediante Acetobacter suboxydans. La L-sorbosa se oxida químicamente a ácido 2-ceto-L-glucónico que por hidrólisis ácida se transforma en ácido L-ascórbico (vitamina C).

II. Vitamina B2. Rivoflavina. Se obtiene por fermentación aerobia con levadura Ashbya gossypii y lípidos como fuente de energía. Los procesos de separación son costosos.

III. Vitamina B12. Cianocobalamina. Se obtiene en una o dos etapas de fermentación aerobia con Pseudomonas denitrificans y Propionibacterium respectivamente. Se obtienen unos 60 $\mathrm{g} / \mathrm{m}^{3}$ en 4 días usando melazas o suero lácteo como sustrato. Los procesos de separación y purificación son también costosos.

d) Carotenoides. Son pigmentos naturales precursores de la vitamina A que solo pueden ser sintetizados por plantas y microorganismos. Se obtienen fermentativamente de Blakeslea trispora con medios viscosos y complejos, requiriéndose la adición de antioxidantes y la recuperación del caroteno mediante la extracción del micelio de los hongos con aceites refinados.

e) Edulcorantes. El aspartamo, mucho más edulcorante que la sacarosa es un metil-éster de dos aminoácidos, L-aspartato y L-fenilalanina, que se producen enzimáticamente o por bacterias.

\subsubsection{Salud}

Es un campo con gran crecimiento por la puesta en marcha de procesos biotecnológicos de producción de fármacos. Mencionaremos algunos productos:

a) Antibióticos. Son compuestos generados por microorganismos, que tienen capacidad para inhibir el crecimiento o destruir otros microorganismos. Los antibióticos naturales son metabolitos secundarios producidos con bajas velocidades de crecimiento o cuando este se ha detenido. La penicilina $\mathrm{G}$ y $\mathrm{V}$ se obtienen por fermentación de 
Penicillium chrysogenium usando como sustratos carbohidratos fermentables ( $2 \%$ de glucosa). La fermentación dura 3-6 días a $\mathrm{pH}$ 6,5 y 25으. Se obtienen unos $30 \mathrm{~g} / \mathrm{L}$ de penicilina, consumiéndose unos $20 \mathrm{~g}$ de carbohidrato por gramo de penicilina producida. Mediante extracciones, filtraciones, enfriamientos y secados se obtienen los cristales de penicilina. Posteriormente se han producido muchos otros antibióticos como estreptomicina, tetraciclina, ciclosporina y posteriormente aparecieron antibióticos sintéticos. Se conocen más de 125 familias de antibióticos con usos muy diferentes en salud humana y animal.

b) Bioinsecticidas. Se busca en ellos mayor especificidad y menor persistencia que los insecticidas químicos. Por ejemplo los productos de fermentación de Bacillus thuringiensis se utilizan contra orugas o mosquitos. Se han obtenido por fermentación con sustratos como harina de soja o extracto de levadura y existen también métodos enzimáticos para obtener estos productos.

c) Fitohormonas. Por ejemplo el ácido giberélico (giberelinas) se obtiene por fermentación con Fusarium monoliforme en fermentadores sumergidos en unos 6 días (se obtiene del orden de 1,2 g/L). Son productos de gran importancia en el desarrollo y crecimiento de las plantas.

d) Esteroides. Hay muchas transformaciones microbianas a partir de la progesterona. Las hormonas esteroideas como la cortisona se pueden obtener por vía química a partir de la bilis bovina en muchas etapas, pero se ha obtenido también por hidroxilación microbiana con Rhizopus arrhizus usando residuos de soja como nutriente.

\subsubsection{Agua y residuos}

Tratamientos medioambientales. Especialmente el tratamiento de corrientes liquidas de subproductos de los vertidos urbanos y las plantas industriales. Según el carácter oxidante (redox) de la degradación suelen clasificarse en:

a) Procesos aerobios. Generándose como productos $\mathrm{CO}_{2}$ y agua con gran producción de biomasa y necesitándose energía para suministrar oxígeno a los aireadores mecánicos, se usan en aguas orgánicas y de baja carga orgánica.

b) Procesos anaerobios. Están bien desarrollados para residuos líquidos con más de $5 \mathrm{~g} / \mathrm{L}$ de DQO, obteniéndose metano y $\mathrm{CO}_{2}$ en una primera aproximación. c) Procesos mixtos. Existen muchos procesos combinados con residuos sólidos y líquidos. Un ejemplo son los residuos en los vertederos, con sólidos que generan residuos líquidos (lixiviados). Existen también procesos para tratar compuestos orgánicos volátiles (COV) en una corriente gaseosa, a través de un proceso previo de absorción en fase acuosa.

\subsection{Fase sólida}

Los procesos en fase sólida son muy diferentes de los de fase líquida, en estos procesos adquieren gran importancia, y pueden llegar a ser controlantes, los procesos difusionales tanto de materia como de calor. Los diseños de estos bioreactores son absolutamente diferentes de los bioreactores en fase líquida donde los procesos de transporte son más intensos. Son muy comunes en el sector alimentario, pero también en el medioambiental/energético y de la salud.

\subsubsection{Alimentos}

a) Pan es el ejemplo más tradicional de fermentaciones en fase sólida. Se usa la levadura del pan (S. cerevisie), la levadura fermenta los azúcares de la masa compuesta por harina, agua y sal. La fermentación dura unas 2 o 4 horas. Se genera $\mathrm{CO}_{2}$ que es muy importante para el esponjado. Es importante la dureza (o fuerza) de la harina en las características del producto final. En el horneado (a unos 200 ㅇ) difunde el gas, quedando los huecos que la estructura genera al cristalizar el gluten. En la cocción también se elimina alcohol dando lugar a aldehídos y otros saborizantes.

b) Lácteos fermentados Quesos. Es un sector de gran importancia económica dentro de la alimentación. Las etapas de producción son: a) tratamiento previo, pasteurización para eliminar bacterias y enzimas, b) Coagulación, por acidificación con starters lácticos que transforman lactosa en ácido láctico o por acción de enzimas que hidrolizan la fracción k-caseina produciéndose la coagulación de la caseína en presencia de calcio. Se suele usar cuajo de ternera, pepsina porcina o productos microbianos (sobre todo de Mucor miehei); c) Separación de cuajada y suero; d) Moldeado de la cuajada y e) maduración para dar aroma y sabor, con enzimas, pero sobre todo con microorganismos (Penicillium, Propionibacterium, etc.)

Leches fermentadas. La fermentación principal la llevan a cabo bacterias lácticas, produciendo 
ácido láctico. El yogurt es el producto mas comercializado de este tipo. Hay muchos microorganismos que se pueden utilizar, Streptococcus thermoplilus, Lactobacillus bulgaricus, Lactobacillus casei, etc.

Mantequilla. La elaboración de la mantequilla es también un proceso microbiológico. Se separa leche (desnatada) de la grasa (mantequilla) durante el batido. Los microorganismos (Streptococcus lactics Subs diacetylactis) crean pequeñas cantidades de acetoína, una sustancia que se oxida de forma espontánea a diacetilo, el compuesto responsable del aroma y sabor de la mantequilla.

c) Cárnicos fermentados. Hay gran cantidad de productos cárnicos curados en procesos fermentativos. Lo que se busca en estos casos son periodos largos de conservación además de producir aromas y sabores característicos. Se utilizan starters en las mezclas de embutición. Se suelen emplear Pediococcus para producir ácido láctico, o Micrococcus que transforman nitratos en nitritos mediante las enzimas nitrato reductasas que estos microorganismos producen. La acción conjunta del nitrito, un $\mathrm{pH}$ de 5,6 a 6 y las bacterias fermentativas producen el curado de los productos.

d) Otros fermentados. Son muy diversos en productos y distribución geográfica.

i. Las coles fermentadas (sauerkraut en alemán, Choucroute en francés). Se forman por fermentación láctica sumergiéndolas en agua con sal, a 20-25 ㅇ produciéndose ácido láctico. Se les puede hacer fermentar también en cerveza o en vino para dar sabor.

ii. Encurtidos. Vegetales (hortalizas normalmente) que se conservan por acidificación. Se cubren de líquido, pueden ser sin fermentación (añadiendo directamente ácido acético-vinagre o totalmente fermentados. Se han utilizado Lactobacillus o Pediococcus para llevar a cabo la fermentación de los azúcares del vegetal y dar lugar a ácido láctico. Las aceitunas, son frutas pero se fermentan como las hortalizas. Se elimina el amargor con una disolución de lejía hasta que penetre hasta la mitad del espesor de la pulpa, después se recubre con salmuera (6-9\%), y se fermentan con Lactobacillus durante 6-10 meses. iii. Fermentados especiales. Algunos productos alimentarios tienen procesos fermentativos asociados, como el té, el café o el cacao. Los procesos fermentativos no se usan para obtener el producto final mediante transformaciones biológicas, sino que la fermentación se usa para separar alguna parte del fruto. Por ejemplo en el café se utilizan pectinasas producidas por mohos como el Aspergillus para eliminar la pulpa que cubre los granos de café. En el cacao la pulpa que recubre las semillas de cacao se eliminan por fermentación durante unos 13 días alcanzando alrededor de 50 ㅇ. Procesos parecidos se producen en la obtención tradicional de la castaña.

iv. Fermentados orientales. Son fermentaciones de diversos granos de cereales como soja, arroz o trigo. Los más importantes son los de soja. Se utiliza Aspergillus oryzae muy usado en cocina oriental, se conoce como Koji. El koji produce una gran cantidad enzimas catalíticas incluyendo la amilasa, que convierte el almidón en azúcares simples.

\subsubsection{Tratamiento de residuos}

Existen muchos procesos que tratan los residuos sólidos desde un punto de vista biotecnológico, así, las técnicas de deposición controlada de residuos urbanos y todo el seguimiento de los procesos de degradación naturales, con gran participación de microorganismos. Otros procesos de fermentación en fase sólida se presentan en los aprovechamientos como el compostaje, la obtención de biogás o la obtención de fertilizantes o piensos.

\subsubsection{Producción de células vegetales}

Se utiliza el cultivo de vegetales en casos que no se pueda obtener suficientemente del suministro forestal, que no puedan ser sintetizados u obtenidos mediante microorganismos. Se obtienen básicamente productos no proteícos, de interés farmacéutico, colorantes, aromas, insecticidas. Existen pocos procesos comerciales que obtengan productos químicos por cultivo de células vegetales. El taxol o la vainillina son algunos. Un campo de desarrollo futuro es el correspondiente a las biofactorias vegetales, utilizando plantas modificadas genéticamente que darán lugar a productos cada vez más demandados por el mercado (vitaminas, aminoácidos, enzimas, etc.). 


\subsubsection{Cultivos de células animales}

Tejidos en implantes en el campo de la salud. El cultivo de muchas células animales se hace en fase sólida. Se requiere el uso de estructuras sólidas sobre las que se colocan las células para su crecimiento. Algunos ejemplos son: i) Tejido hematopoyético, se encuentra en la médula ósea produciendo glóbulos blancos y rojos. Se puede desarrollar ex-vivo a partir de muestras de hueso; ii) Hígado artificial y otros órganos, se combinan materiales de soporte y biológicos; iii) para obtener piel se cultivan sobre una matriz de colágeno fibroblastos dérmicos, para dar lugar al crecimiento epitelial. La ingeniería tisular estudia la formación de tejidos de diferentes órganos basados en células animales o proteínas a las que se debe conferir una funcionalidad similar al tejido al que van sustituir especialmente en torno al suministro de nutrientes (sobre todo $\mathrm{O}_{2}$ ) y a la transferencia de energía.

\section{TRANSFORMACIONES INDUSTRIALES CON ENZIMAS}

El uso de enzimas está muy extendido en procesos industriales. El coste del biocatalizador (el enzima) representa un porcentaje importante en el coste total del proceso. En la purificación industrial de las enzimas el coste es aun mayor cuando se necesita alta pureza requiriéndose técnicas costosas (cromatografía, electroforesis) para su purificación industrial. Algunos usos son:

\subsection{Industria de la alimentación}

Se utilizan en la elaboración de numerosos productos. Así para pan (proteasas, lipoxidasas), lácteos y quesos (enzimas lipolíticas y proteolíticas, tales como renina, lactasa, etc.), yemas de huevo desecada (glucosa-oxidasa), frutas y zumos (pectina, glucosa-oxidasa, amilasa, invertasa, naringinasa, etc.). Hay diversas aplicaciones directas, por ejemplo para ablandar carne, la papaína (obtenida de la papaya) degrada las proteínas del tejido conectivo.

Las proteasas se usan para degradar las proteínas del gluten (gluteninas y glianidinas). Las pectinasas obtenidas con Aspergillus y Rhizopus se usan para degradar la pectina de las frutas. La malta que contiene un 0,5-1 \% de amilasas, es uno de los mayores suministradores de enzimas. Las transglutaminasas (TGM) son enzimas transferasas capaces de unir proteínas entre un grupo amino de un residuo de lisina y un grupo carboxamida de un residuo de glutamina. De esta manera, son capaces de crear un enlace inter o intramolecular altamente resistente a la proteolisis, es de- cir, la ruptura de la proteína. Estos enzimas se utilizan para reconstituir carne en algunas aplicaciones de la industria cárnica.

\subsection{Otros usos industriales}

Hay numerosas aplicaciones, así en la industria textil, cuero, aditivos en piensos (para mejorar la digestión), farmacéutica (diversos medicamentos para dispepsias: pancreatina, renina, pepsina, tripsina, catalasa, lipasa, etc.; pomadas para traumatismos: hialuronidasa; o para hematomas: estreptoquinasa, etc.), y en cosmética (papaína en depilatorios, etc.). Comentaremos algunos productos que requieren el uso de enzimas.

\subsubsection{Hidrólisis de polisacáridos}

Las amilasas tienen un amplio uso en la hidrólisis de almidones. Las $\alpha$-amilasas a 80-105 ㄷ generan dextrinas (hasta maltosa) que se transforman en glucosa mediante glucoamilasa a pH de 6,7-7. Las $\alpha$-amilasas se obtienen con Bacillus y la glucoamilasa con Aspergillus. En la Figura 2 se muestra el proceso de producción de bioetanol, en el cual una de sus operaciones principales son las hidrólisis de los polisacáridos para convertirlos en azúcares fermentables.

\subsubsection{Transformación de glucosa en fructosa}

La fructosa tiene el doble de poder edulcorante que su isómero la glucosa. La glucosa se forma de almidón y se isomeriza industrialmente mediante la glucosa isomerasa, que se puede producir mediante Streptomyces spp. Si la enzima se inmoviliza se puede reducir el coste de producción final en un $40 \%$.

\subsubsection{Producción de aminoácidos esenciales}

El proceso tradicional era el aislamiento de L-aminoácidos a partir de hidrolizados de proteínas. Al obtenerlos químicamente se produce una mezcla racémica. Estas mezclas racémicas pueden tratarse enzimáticamente (por ejemplo con aminoacilasa de $A$. oryzae) obteniéndose el L-aminoácido (poco soluble) y el $D$ acetilado que se separan fácilmente.

\subsubsection{Glutamato}

Hacia 1950 se realizó la búsqueda de las bacterias para obtener glutamato, diseñándose un sistema a partir de C. glutamicum. La producción anual es superior a 750000 toneladas al año, dividida entre una docena de empresas. Como sustrato se suelen usar 
Figura 2. Esquema de la producción de bioetanol a partir de cereales

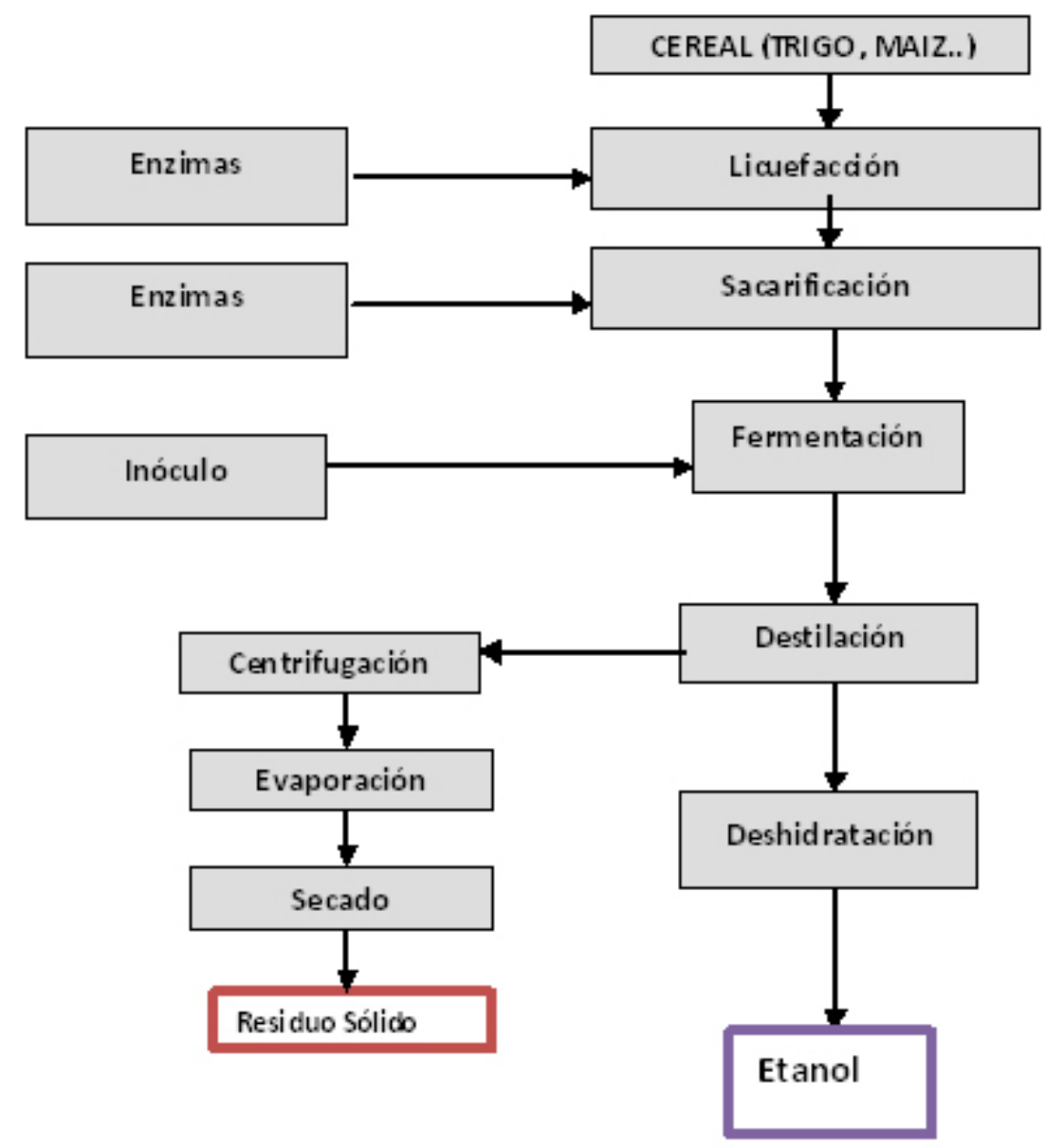

melazas o almidón hidrolizado, aparte de alguna fuente adecuada de nitrógeno, como pueden ser sales amónicas. Se han usado mutantes sensibles a la temperatura para que la bacteria secrete el glutámico al medio. La producción es de alrededor de $50 \mathrm{~g}$ de glutámico por litro, con un rendimiento del $40 \%$ de la glucosa transformada en glutamato.

\subsection{Enzimas en fase orgánica}

Se utilizan sobre todo hidrolasas (más concretamente lipasas y proteasas) para realizar síntesis orgánicas en condiciones suaves de operación. Una de las ventajas de estos procesos es que presentan quimio y enantioselectividad. El trabajar en disolventes orgánicos facilita en algunos casos la biocatálisis cuando se quieren producir reacciones desfavorables en agua, la supresión de reacciones colaterales inducidas por agua o la recuperación de las enzimas por ser insolubles en disolventes orgánicos.

\subsection{Uso directo: Detergentes}

En la fabricación de detergentes se han utilizado complejos enzimáticos. La suciedad puede contener grasas y proteínas, las grasas pueden ser eliminadas mediante tensoactivos, mientras que las proteínas pueden ser atacadas por las proteasas para dar péptidos de fácil eliminación. Aproximadamente un $2 \%$ del peso del disolvente son proteasas y suelen introducirse granuladas. Para otros tipos de limpieza, por ejemplo membranas industriales, se usan celulasas. Existen cada vez más productos comerciales que se han desarrollado como detergentes enzimáticos, con amplios espectros de uso.

\subsection{Usos en medicina}

El estudio y uso de las enzimas en farmacología y medicina son muy importantes. A nivel de investigación se trabaja mucho en estudiar la funcionalidad o 
disfuncionalidad de las enzimas en el organismo. La industria derivada de la farmacología enzimática no tiene grandes volúmenes aunque sí son productos de gran valor añadido. Es una industria que en los próximos años dará lugar a muchos nuevos productos.

\section{APROVECHAMIENTO DE MATERIALES BIOLÓGICOS}

Muchos materiales biológicos, unos de crecimiento agrario o boscoso y otros de crecimiento animal, presentan importantes usos industriales. Muchas veces no son transformaciones biológicas sino simplemente procesos de hidrólisis y de separación. Las aplicaciones y usos de este tipo de materias primas requieren conocer con bastante detalle la estructura de los materiales biológicos. Es evidentemente clave disponer de la producción primaria suficiente. En el caso de aprovechamiento de residuos es importante el mercado y los condicionantes legales que puede haber. Distinguiremos y mencionaremos algunos productos de origen vegetal y animal.

\subsection{Origen vegetal}

\subsubsection{Materiales de almacenamiento de hidratos de carbono}

El ejemplo más conocido es la producción de azúcar (sacarosa) a partir de caña de azúcar o remolacha. Otro ejemplo es la producción de polisacáridos a partir de algas, por ejemplo la obtención de alginato, agar o carragenato a partir de Gelidium.

\subsubsection{Materiales de construcción celular vegetal}

Se toma como base la madera (material lignocelulósico) con usos tradicionales en construcción bien conocidos. Un uso como materia prima industrial es su transformación en papel que actualmente pueden combinarse con la producción de energía a partir de residuos de materias primas o del proceso de elaboración.

\subsubsection{Aprovechamiento de aceites}

Los aceites son base para la producción de muchos productos alimentarios, farmacéuticos y químicos, por ejemplo la producción de biodiesel a partir de aceites usados.

\subsection{Origen animal}

El uso de productos de origen animal está muy extendido en los procesos biotecnológicos indus- triales. Los principales productos se centran en estos sectores:

\subsubsection{Alimentario}

Se incluirían aquí todos los procesos de transformación de materias primas en alimentos sin fermentación. Por ejemplo en el sector cárnico la producción de productos cocidos, o el sector de platos preparados o precocinados.

\subsubsection{Pieles, cueros y plumas}

Las pieles y los cueros tienen un conocido uso en sector de la ropa y complementos. De las plumas de aves de corral se puede obtener queratina mediante procesos hidrolíticos, usándose en los sectores farmacéutico y cosmético.

\subsubsection{Hormonas}

Los animales son una fuente de hormonas muy importante en el sector médico y farmacéutico. Algunas glándulas de animales ya han sido utilizadas antiguamente por sus poderes curativos. Todas ellas no constituyen más del $0.3 \%$ del peso total del animal. Estas glándulas endocrinas segregan hormonas de usos farmacéuticos. La cortisona (regula el metabolismo de las grasas y carbohidratos), adrenalina; Bilis, para síntesis de corticoesteroides ya que contienen ácido cólico y desoxicólico. Del cerebro, se obtiene colesterol (síntesis de vitamina D), tromboplástina (coagulante sanguíneo) y cefalina. Del hígado, vitamina B12 (cianocobalamina, tratamiento de anemias), catalasa (procesado de alimentos), harina de hígado (riboflavina). De los pulmones, heparina. De la médula espinal, hormonas sexuales. Del páncreas, insulina (regulación del metabolismo del azúcar), quimiotripsina, pancreatina, tripsina, etc. De la glándula pineal (localizada en la cabeza por delante de la pituitaria), se extrae la hormona melanógena usada para el tratamiento de algunas enfermedades mentales. De la pituitaria, hormonas de crecimiento, estimulantes del tiroides y del tiroides la hormona tiroxina. En este campo compiten los métodos tradicionales de extracción con desarrollos de la química sintética que en algunos casos han dado lugar a la hormona.

\subsubsection{Grasas animales}

Se suelen denominar sebos a las grasas fundidas de vacuno y ovino y manteca a la grasa de cerdo. Estas definiciones están relacionadas con la temperatura de fusión de las grasas. Sebos y mantecas son sólidos a 
temperatura ambiente mientras que aceites (generalmente de origen vegetal) son líquidos a temperatura ambiente.

\subsubsection{Harinas de carne y huesos}

Es el producto, que una vez secado, acompaña al sebo en los procesos de fusión de desechos. Este es un producto muy rico en nitrógeno, fósforo y calcio y en la actualidad se utiliza como integrante de piensos para animales. Puede contener altos contenidos de proteínas (hasta el $60 \%$ ). Si contienen más de un $4.4 \%$ de fósforo se denominan "harina con huesos". Dependiendo del tipo de proceso que se utilice en la fusión la harina puede tener un valor proteínico superior (vía de fusión seca), la harina de huesos especial se prepara a partir de huesos limpios de grasa y carne.

\subsubsection{Aprovechamiento de proteínas residuales}

Existen materias de origen animal que tienen un carácter residual y que tienen un alto contenido proteico. Estos residuos suelen tener también un elevado coste para su destrucción, por lo que los procesos para su aprovechamiento tienen interés particular. La sangre residual de mataderos es un subproducto de difícil revalorización aunque contiene elevadas cantidades de proteínas aprovechables. Tradicionalmente se ha utilizado el plasma como aditivo alimentario, sobre todo en productos cárnicos (conservas, precocinados, etc.). También se han desarrollado métodos para obtener y utilizar la globina, proteína mayoritaria de la fracción celular de la sangre, mediante su decoloración para su uso en alimentación (Figura 3). También se puede aprovechar las fracciones del plasma.

Figura 3. Procesos de aprovechamiento de las proteínas de la sangre residual de mataderos

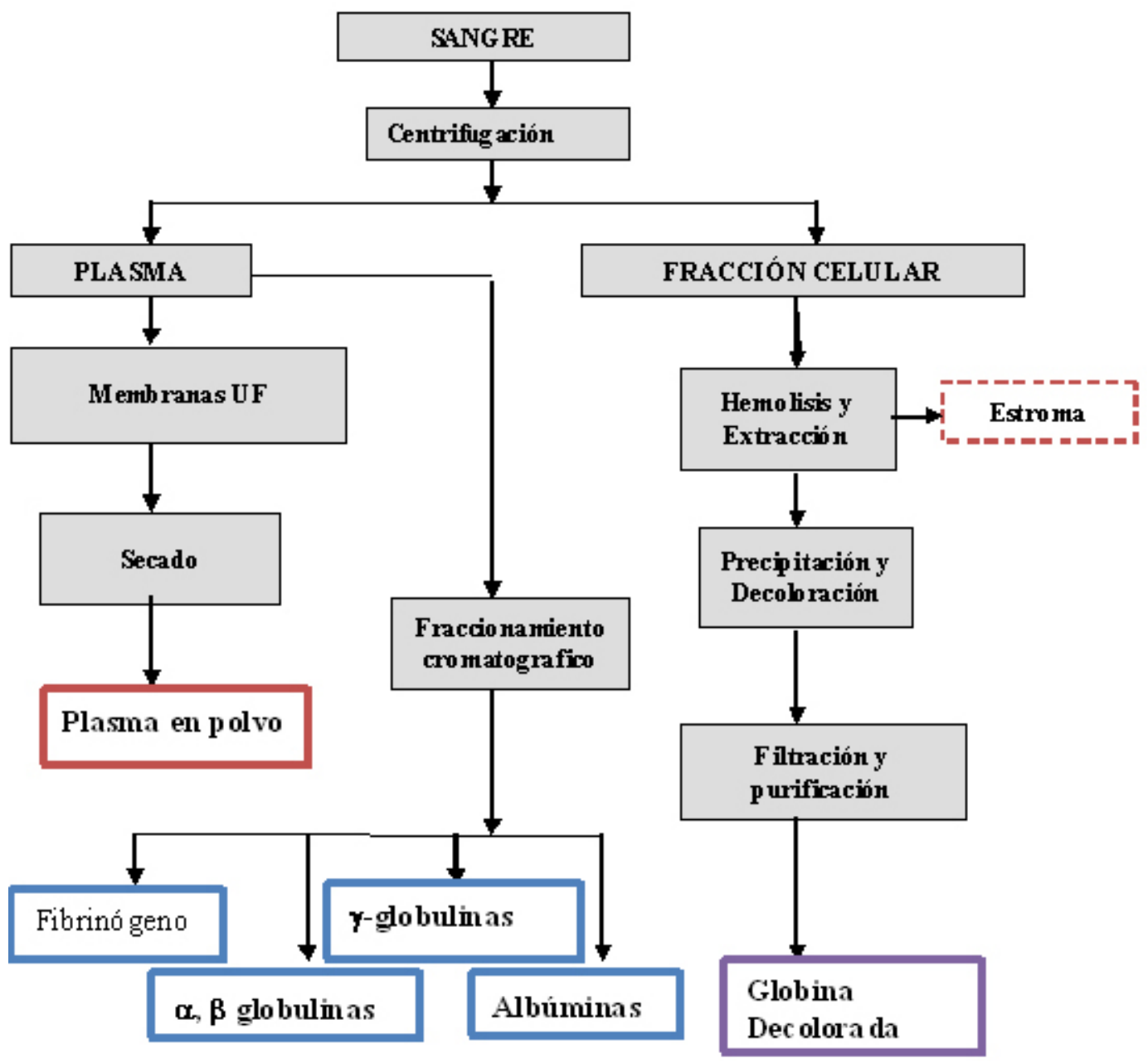


La cola y la gelatina son proteínas coloidales hidrófilas obtenidas por hidrólisis controlada del colágeno (insoluble en agua), que es una proteína fibrilar muy común en los animales. La cola y la gelatina son parecidas estructuralmente y se diferencian en que la gelatina se obtiene de materias primas frescas y por tanto es apta para el consumo humano. No pueden aportar todos los aminoácidos esenciales para el organismo. Sin embargo, se utiliza como aditivo de alimentos y como agente de interés terapéutico en dietas infantiles, casos de úlceras pépticas, desordenes musculares, etc. Por el contrario, la gelatina es muy rica en prolina e hidroxiprolina. El colágeno puede representar alrededor de un $30 \%$ de toda la materia orgánica del animal y alrededor de un $60 \%$ del contenido proteínico total.

\section{VENTAJAS, DIFICULTADES Y PERSPECTIVAS}

La biotecnología industrial tiene unas grandes expectativas de desarrollo en un futuro próximo. Los trabajos que la ciencia básica y la ingeniería llevan desarrollando en todos los campos de la biotecnolo- gía desde hace muchos años son la base fundamental en el desarrollo de nuevos procesos industriales. Aspectos relacionados con la genómica, la proteómica y la bioinformática darán lugar al desarrollo de nuevos productos y fármacos que serán producidos a escala industrial o semiindustrial, y para ello la ingeniería de procesos jugará un papel clave llevando los desarrollos de laboratorio a planta piloto y posteriormente a plantas industriales.

La biotecnología industrial se plantea como una alternativa a otros procesos que parecen ser menos sostenibles. La disminución del impacto medioambiental de los procesos biotecnológicos es uno de los factores que esta industria presenta para su desarrollo. Sin embargo debe demostrarse bien este aspecto en el camino hacia la competitividad. En todo caso y dada la variedad de campos de los que aquí simplemente se han citado algunos la Biotecnología Industrial resulta un sector industrial con fuertes perspectivas de desarrollo en prácticamente todos los sectores industriales a escala global.

\section{BIBLIOGRAFÍA}

Atkinson, B. y Mavituna, F. (1983). Biochemical Engineering and Biotechnology Handbook. London: Macmillan.

Díaz, M. (2012). Ingeniería de Bioprocesos. Madrid: Paraninfo.
García, J. L. (2004). Ingeniería genética y biotecnología. Monografías de la Real Academia Nacional de Farmacia, Monografía XV: Nuevos avances en medicamentos, pp. 199-236.
Sánchez Montero, J. M. (2007). Biotecnología blanca e industria farmacéutica. Anales de la Real Academia Nacional de Farmacia, 73, pp. 501-535. 